\title{
Microstructure and Properties Characterization of WC-Co-Cr Thermal Spray Coatings
}

\author{
Karla Ofelia Méndez-Medrano¹, Cecilio Jesús Martínez-González¹, \\ Francisco Alvarado-Hernández ${ }^{1}$, Omar Jiménez ${ }^{2}$, Víctor Hugo Baltazar-Hernández ${ }^{1}$, \\ Haideé Ruiz-Luna ${ }^{3 *}$ \\ ${ }^{1}$ Unidad Académica de Ingeniería, Universidad Autónoma de Zacatecas, Zacatecas, México \\ ${ }^{2}$ CUCEI, Universidad de Guadalajara, Jalisco, México \\ ${ }^{3}$ Unidad Académica de Ingeniería, CONACYT-Universidad Autónoma de Zacatecas, Zacatecas, México \\ Email: `hruizlu@conacyt.mx
}

How to cite this paper: Méndez-Medrano, K.O., Martínez-González, C.J., AlvaradoHernández, F., Jiménez, O., BaltazarHernández, V.H. and Ruiz-Luna, H. (2018) Microstructure and Properties Characterization of WC-Co-Cr Thermal Spray Coatings. Journal of Minerals and Materials Characterization and Engineering, 6, 482-497. https://doi.org/10.4236/jmmce.2018.64034

Received: June 2, 2018

Accepted: July 14, 2018

Published: July 17, 2018

Copyright $\odot 2018$ by authors and Scientific Research Publishing Inc. This work is licensed under the Creative Commons Attribution International License (CC BY 4.0).

http://creativecommons.org/licenses/by/4.0/

\begin{abstract}
WC-Co-Cr coatings are widely employed due to their improved wear resistance and mechanical properties, however, the properties and performance of these coatings are compromised by the processing parameters of each spraying technique. Therefore, this study is aimed to evaluate and determine the effect of the deposition parameters on the properties and microstructural characteristics of WC-Co-Cr coatings using a more economical thermal spray technique. In particular, the influence of flame spray parameters on the microstructure, crystal structure, hardness, and sliding wear resistance of WCCo-Cr coatings was examined. Two parameters were considered: Type of flame (reducing, neutral and oxidizing), and the spray torch nozzle exit area. Results indicated that WC particles undergo considerable degree of decarburization and dissolution during spraying, showing substantial amounts of $\mathrm{W}_{2} \mathrm{C}, \mathrm{W}$, and $\mathrm{Co}_{3} \mathrm{~W}_{3} \mathrm{C}$, for all the considered conditions. However, the extent of phase transformation depended largely on the flame chemistry. The microstructure of the coatings was mainly affected by the spray nozzle. Regarding the sliding wear behavior, the coatings with uniform distribution of hard particles provided the best wear resistance. The decomposition of $\mathrm{WC}$ into $\mathrm{W}_{2} \mathrm{C}$ phase seems to have meaningless significance in the mass loss, nevertheless, the WC phase transformation to metallic tungsten and $\eta$-phase $\left(\mathrm{Co}_{3} \mathrm{~W}_{3} \mathrm{C}\right)$ produce higher wear rates due to deficiency of carbide particles and embrittlement of the binder phase which induces cracking and delamination of the splats.
\end{abstract}

\section{Keywords}

WC-Co-Cr Thermal Spray Coating, X-Ray, Phase Content, Microstructure, 
Flame

\section{Introduction}

Tungsten carbide cermets with cobalt and chromium additions (WC/Co-Cr) are widely used for wear- and corrosion-resistant applications in different industrial sectors including aeronautic, mining and automotive. For instance, these materials have been proposed for the replacement of electrolytic hard chromium commonly used in aircraft shafts and landing gears due to their high hardness, and superior friction and abrasion resistance [1] [2].

Different thermal spray processes, such as high velocity oxy-fuel (HVOF) [1] [3] [4] [5], air plasma spraying (APS) [6] [7], and detonation gun (DG) [2] [8], have been mainly employed to deposit tungsten carbide coatings. These techniques have been investigated with respect to the structural and microstructural characterization, mechanical properties and wear resistance of WC-cermet powders and coatings [4] [5] [7] [9] [10]. Alternative to these spraying techniques, which indeed requires considerable initial financial investment and higher material cost, the flame spray process has been employed to deposit different materials including wear-resistant coatings [11] [12] [13]. Notwithstanding this technique generates low flame temperatures and velocities and coatings with high porosity content [14], it is still employed due to its low-energy consumption, adaptable aspects, more environmental friendly, and in addition, offers a low-cost choice for commercial applications [12] [13] [15].

The decomposition of WC particles is the main phenomenon that occurs during thermal spraying. Excessive temperatures during deposition may cause extensive decomposition or decarburization of $\mathrm{WC}$ particles resulting in the formation of several phases such as $\mathrm{W}_{2} \mathrm{C}, \eta-\mathrm{Co}_{\mathrm{x}} \mathrm{W}_{\mathrm{y}} \mathrm{C}_{\mathrm{z}}\left(\mathrm{Co}_{6} \mathrm{~W}_{6} \mathrm{C}\right.$ and $\left.\mathrm{Co}_{3} \mathrm{~W}_{3} \mathrm{C}\right)$, dissolution of metallic tungsten and carbon in the binder phase, as well as the formation of an amorphous Co phase due to the rapid solidification during impact [4] [10] [16] [17]. However, the microstructure and performance of the WC/Co-Cr coatings depend not only on the thermal spray system [3] [5] [10] [18], but also significantly on the spray parameters, feedstock powder particles (type, morphology, composition), and the fuel type employed [16]. Moreover, tungsten carbide coatings present a broad range of properties and microstructural features as a function of phase content, powder and carbide grain size, distribution of the carbide particles [5] [9] [10] [19], porosity content [4] [7] [20], and the cohesion of the WC particles with the Co matrix [3] [8] [10].

Considering that the flame spray process produces low particle velocities and temperatures, and the compositional and microstructural characteristics of thermally spray coatings depend on the processing parameters [3] [5] [6] [9] [16] [17] then, it is essential to investigate the effect of the spraying parameters on the microstructure of the coatings. No similar studies have been conducted 
for WC-Co-Cr coatings that present the influence of the flame spray parameters on the coatings characteristics. Therefore, this research intends to compare and analyze the microstructural features, phases and properties of WC-Co-Cr coatings as a function of different processing parameters.

\section{Experimental Procedure}

\subsection{Materials and Coating Deposition Technique}

In this study, commercial, agglomerated and sintered WC-10Co-4Cr (wt. \%) feedstock powder with particle size -45 to $+11 \mu \mathrm{m}$ was employed.

A CastoDyn DS 8000 (Castolin Eutectic) flame spray gun operated with a mixture of oxygen and acetylene was used for coating deposition. The coatings were deposited onto grit-blasted low carbon ASTM A36 steel plates of $50 \times 25 \times$ $4 \mathrm{~mm}$ for microstructure analysis and ASTM A36 cold rolled pins of $10 \mathrm{~mm}$ diameter for wear testing. In order to identify and estimate the effect of the flame on the WC-Co-Cr coatings, samples were sprayed using three flame combinations: reducing or carburizing, neutral, and oxidizing, by varying the acetylene gas flow. Additionally, three different nozzles designed specifically to the DS 8000 torch were also investigated. All the nozzles, labelled as N1, N2 and N3, have the same length with a straight duct connected to the outlet of the converging section but its exit area is different. According to the measurements, the nozzle N3 has the smallerexit area $(\phi=1.5 \mathrm{~mm})$, followed by N2 $(\phi=2.4 \mathrm{~mm})$ and $\mathrm{N} 1$ exhibits the highest exit area $(\phi=4.8 \mathrm{~mm})$.

For all conditions tested (see Table 1), the acetylene and oxygen pressures were kept constant at 0.7 and 4 Bar, respectively. The feedstock powder was sprayed at a stand-off distance of $200 \mathrm{~mm}$ and the number of torch passes was one in all cases.

\subsection{Characterization Techniques}

Coatings were evaluated by $\mathrm{X}$-ray diffraction (XRD) using $\mathrm{Cu}-\mathrm{Ka}$ radiation on a

Table 1. Spray parameters for WC-Co-Cr coatings along with porosity content of the deposited coatings.

\begin{tabular}{cccc}
\hline Coating designation & Type of flame & Nozzle & Porosity (\%) \\
\hline N1R & Reducing & N1 & $16.7 \pm 1.6$ \\
N1N & Neutral & N1 & $14.7 \pm 1.7$ \\
N1O & Oxidant & N1 & $15.9 \pm 1.9$ \\
N2R & Reducing & N2 & $17.1 \pm 1.4$ \\
N2N & Neutral & N2 & $14.9 \pm 2.6$ \\
N2O & Oxidant & N2 & $18.9 \pm 1.9$ \\
N3R & Reducing & N3 & $6.6 \pm 1.2$ \\
N3N & Neutral & N3 & $6.4 \pm 0.7$ \\
N3O & Oxidant & N3 & $8.0 \pm 1.0$ \\
\hline
\end{tabular}


D8Advance Bruker diffractometer. The cross section of the coatings were characterized using a field emission scanning electron microscope (FESEM, Tescan Mira3) equipped with an energy-dispersive X-ray spectrometer (EDS). The porosity percentage of the samples was determined by image analysis from eight cross-section images.

Vickers microhardness measurements were performed along the thickness of the coatings using a Shimadzu tester under a load of $100 \mathrm{~g}$ and dwell time of 15 s. An average of five indents was carried out at each position.

Wear testing was performed using a pin-on-disk machine according to ASTM G-99 standard. Wear specimens were prepared in the form of cylindrical pins with a radiused tip in order to maintain consistent initial contact area. AISI/SAE-D2 tool steel in the form of $100 \mathrm{~mm}$ diameter and $10 \mathrm{~mm}$ thickness disc plate was employed as the counterface. The steel disc plate was quenched and tempered in order to achieve hardness value of about $64 \mathrm{HRC}$, in addition, the plates were ground at the surface with the purpose of achieving a surface roughness $R a<0.6 \mu \mathrm{m}$. The pin samples were subjected to 15,30 , and $50 \mathrm{~N}$ loading at $400 \mathrm{rpm}$ during $900 \mathrm{~s}$. In order to calculate the mass loss, the specimens were weighed and cleaned with acetone before and after testing using an electronic weighing balance with an accuracy of $\pm 10^{-3} \mathrm{mg}$. A minimum of six samples were tested for each experimental condition. The morphology and chemical composition of the wear debris were analyzed by SEM.

\section{Results and Discussion}

Figure 1 shows the XRD patterns of the powder particles and the as-sprayed coatings. The X-ray pattern of the feedstock powder identified WC as the major phase, and traces of $\mathrm{Co}$ and $\mathrm{Co}_{3} \mathrm{~W}_{3} \mathrm{C}$. Besides the WC peaks, the corresponding to $\mathrm{W}_{2} \mathrm{C}, \mathrm{W}$, and $\mathrm{Co}_{3} \mathrm{~W}_{3} \mathrm{C}$ phases were detected for all the as-sprayed coatings, showing that $\mathrm{WC}$ decarburization and dissolution occurred during the spraying process of the powder particles, as described elsewhere [5] [16] [17] [21] [22]. The Co phase was no longer noticed and instead, two broaden peaks, the first in the $37^{\circ}$ to $45^{\circ}$ range, and the second between $68^{\circ}$ and $80^{\circ}$, are distinguished for all the coatings, however, these peaks are more noticeable for coatings sprayed with nozzle N3 than for N2 and N1. These widen peaks, recognized as an $\eta$-phase, correspond to the binder matrix which is often predominantly in the form of nano-sized crystals or amorphous state due to the high cooling rates of the sprayed particles during the solidification process [9] [16] [17] [21]. The presence of the amorphous phase observed in the XRD patterns for the coatings deposited using nozzle N3 (Figure 1(c)), indicates that the cooling rates of the sprayed particles are higher than those reached by the particles deposited using nozzle N1 and N2. As described later, nozzle N3 produces the highest velocity of the powder particles, compared to N2 or N1 nozzles, which decreases the temperature and residence time of the particles in the flame resulting in rapid cooling rates of the sprayed particles [23]. High cooling rates lead to the formation of 

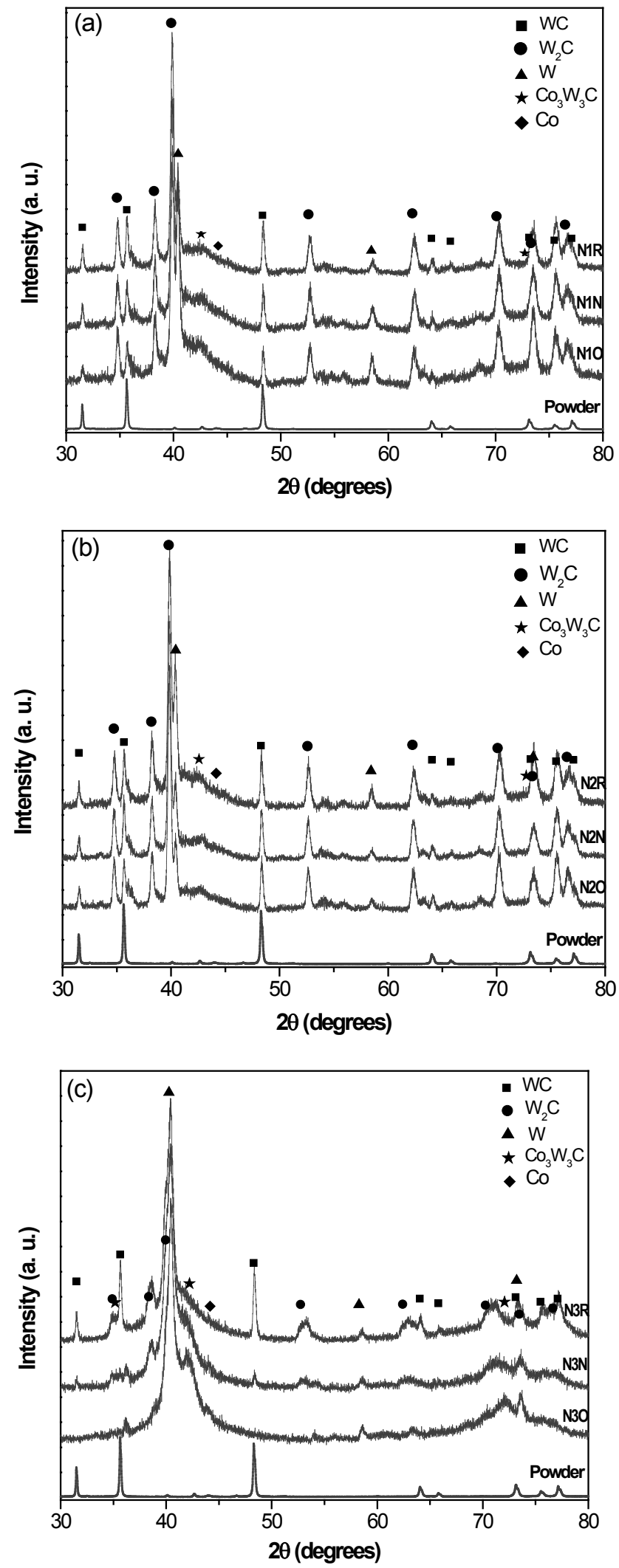

Figure 1. XRD patterns of the flame sprayed coatings deposited using nozzle (a) N1, (b) $\mathrm{N} 2$, and (c) N3. 
amorphous phases because the atomic diffusion and the nucleation rates decrease [24]. Moreover, this high cooling rate and thus the presence of the amorphous structure, is favored by the thin lamella microstructure of the coatings deposited with nozzle N3 (Figures 2(g)-(i)) [23]. On the contrary, low velocity and high temperature of the in-flight particles decrease the cooling rates and increase the crystallization phenomena during solidification (Figure 1(a) and Figure 1(b)).

Although the diffraction patterns are quite similar for the coatings, an interesting effect is noted in terms of type of flame for the samples deposited with nozzle N3. It is clearly observed in Figure 1(c), that WC peaks are most pronounced for the coating sprayed with a fuel-rich flame (N3R) whereas the relative intensities of this phase are diminished or almost entirely disappeared for samples deposited with a neutral and/or oxidizing flame (N3N and N3O). A semi-quantification of the relative phase content detected by the XRD patterns was performed by DiffracEVA software. The analysis indicated that sample N3R, deposited with a fuel-rich flame, retained the highest WC content ( 24\%) compared to the coatings sprayed using a neutral- $(\mathrm{N} 3 \mathrm{~N})$ and oxygen-rich $(\mathrm{N} 3 \mathrm{O})$ flame which shows a greater extent of decarburization (significant presence of elemental $\mathrm{W}$ and $\mathrm{Co}_{3} \mathrm{~W}_{3} \mathrm{C}$ peaks) and the corresponding to $\mathrm{WC}$ phase is reduced to a minimum (5 and 2\%, respectively). This behavior is related to fuel-rich chemistry condition which causes low particle temperatures and high particle velocities [25] [26]. On the contrary, high temperatures and longer residence times of the particles are obtained for the neutral and oxidizing flames causing a higher degree of decomposition of the tungsten carbide particles. In general terms, decarburization of tungsten carbide thermal spray coatings is reduced if lower temperature flames are employed [3] [4] [17] [27].

The cross section of the coatings is shown in Figure 2. As observed in the micrographs, the WC-Co-Cr coatings microstructure is quite similar for the samples deposited with nozzles N1 and N2 (Figures 2(a)-(f)). A lamellar structure is not observed for the coatings and instead, a non-uniform microstructure, with large amounts of unmolted and partially molten particles, some oxide stringers and porous regions, is revealed. The limited flattening of the powder particles is attributed to low particle velocities which causes less degree of particle deformation at impact [2] [3] [4], and the porosity content (Table 1) is consequence of the poor flattening and a heterogeneous melting of the powder particles during spraying [28]. Notwithstanding, these coatings showed the presence of rounded carbide particles with different grain sizes dispersed along its microstructure. On the contrary, a pattern of flattened splats parallel to the substrate surface with lower porosity (Table 1) and oxides stringers are observed for N3 coatings (Figures 2(g)-(i)). Particularly, the morphology of these coatings presents meaningful differences regarding the type of flame utilized. Notably, tungsten carbide particles are distributed in the majority of the splats of the sample deposited with a carburizing flame (N3R, Figure $2(\mathrm{~g})$ ) while for the N3N and N3O samples (Figure 2(h) and Figure 2(i), respectively) the hard grains have almost 
completely disappeared leaving a cobalt containing-subcarbides and tungsten-rich layered structure binder phase. The absence of carbide particles in the splats for these two coatings reveals that a dissolution of the WC particles into the Co matrix occurred during deposition, causing the volume of the binder phase to increase at its expense. This result is quite consistent with the X-ray diffraction analysis where high concentrations of $\mathrm{W}(\sim 36 \%)$ and $\mathrm{Co}_{3} \mathrm{~W}_{3} \mathrm{C}$ (increased from $\sim 9 \%$ to $\sim 36 \%)$ were obtained. The larger degree of decarburization of the N3N and $\mathrm{N} 3 \mathrm{O}$ flame sprayed coatings may be attributed to the high temperature and oxidizing conditions of the flame.

It is worth mentioning that irrespective of the nozzle and flame, the tungsten carbide grains present in the coatings exhibit a more rounded morphology and are composed of WC grains surrounded by $\mathrm{W}_{2} \mathrm{C}$ in accordance to Jacobs et al., [22], Stewart et al., [29], and Verdon et al., [21]. This behavior is an indicative of the dissolution of tungsten carbide particles during spraying.

Based on the microstructural analysis, the nozzle exit area has an influence on the resultant coating morphology. In particular, the combustion gases of the flame spray technique can be treated as an incompressible flow, which follow the principles of fluids dynamic, because the gas velocity $(<100 \mathrm{~m} / \mathrm{s})$ is much lower
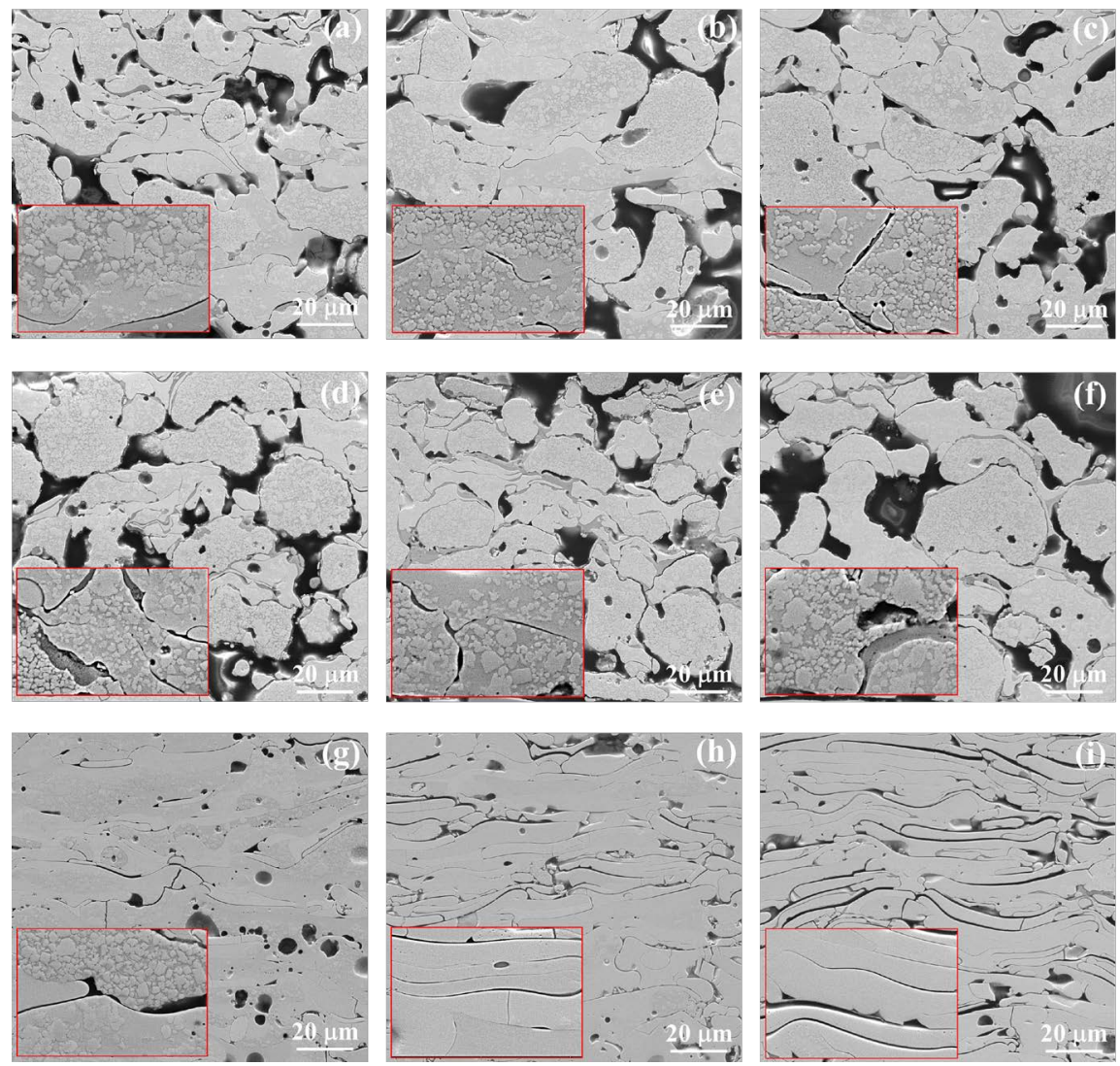

Figure 2. Cross-section of the flame sprayed WC-Co-Cr coatings deposited using nozzle: N1 (a)-(c), N2 (d)-(f) and N3 (g)-(i) and type of flame employed: carburizing (a, d, g), neutral $(b, e, h)$ and oxidizing $(c, f, i)$. Detailed observation on the corresponding microstructure has been included in the inset. 
compared to Mach 1 [14]. Therefore, it is expected that the velocity of the gas flow increases as the nozzle exit area decreases [30]. A high velocity or small exit area (nozzle N3) is associated with a high degree of plastic deformation during impact, i.e., coatings with lamellar microstructure and low porosity as observed in Figures 2(g)-(i), while the microstructure of the coatings deposited with a higher nozzle exit area (N1 and N2, Figures 2(a)-(f)), is attributed to a lower velocity reached by the particles, which is insufficient to plastically deform the particles at impact.

Considering the thermal energy of the flame on the coatings features, the highest the heat transferred from the flame to the WC-Co-Cr powder particles the more decomposition reactions of WC proceed. Therefore, decreasing the heating ability of the flame and/or increasing its velocity, which reduces the residence time of the particles in the flame, allows for lower levels of decarburization and dissolution of the WC particles [5] [9] [22] [29]. In general, the flame temperature of combustion spray processes is greatly influenced by the flame chemistry or stoichiometry [14]. Fuel-rich or reducing conditions generate high particle velocities and low energy flames [25] [26], whereas neutral and oxidizing conditions produce high temperature and low velocities of particles allowing a high degree of particle oxidation as a consequence of longer residence times in the flame. This is consistent with the XRD analysis which shows that moving from fuel- to oxygen-rich flames less retained WC particles and more decarburization and reaction with the binder phase is detected in the coatings.

The microhardness indentation profile along the WC-Co- $\mathrm{Cr}$ coatings is provided in Figure 3 for all assessed conditions. As observed, quite consistent hardness distribution through the coating thickness resulted in all tested conditions; however, the coatings deposited with $\mathrm{N} 1$ and N2 nozzles are harder than the coatings sprayed using N3 nozzle. The lower hardness values measured for $\mathrm{N} 3$ condition can be clearly attributed to the lower content of hard phases (i.e., $\mathrm{WC}$ and $\mathrm{W}_{2} \mathrm{C}$ ) which is in agreement with XRD and SEM results (Figure 1 and Figure 2, respectively). It is worth to mention here that the observed dispersion in all hardness data was highly influenced by the inherent microstructural features within the coatings such as: carbide size and distribution, fraction of hard phases at individual splats, porosity content, and level of cohesion with the binder phase [1] [10] [22] [31] [32]. In particular, in the present study, the dispersion of the hardness values is attributed to the high porosity content (open and interlamellar), voids, and poor splat cohesion of the coatings as observed in Figure 2.

The sliding wear behavior as a function of normal load of WC-Co-Cr coatings for all tested conditions is observed in Figure 4. As observed, the mass loss of the coatings increases as the normal load increases. The samples deposited with $\mathrm{N} 1$ and N2 nozzles showed the lower mass loss and the higher mass loss resulted for $\mathrm{N} 3$ conditions irrespective of the applied normal load. Among all tested conditions, enhanced wear performance was observed for $\mathrm{N} 2$ coatings. 

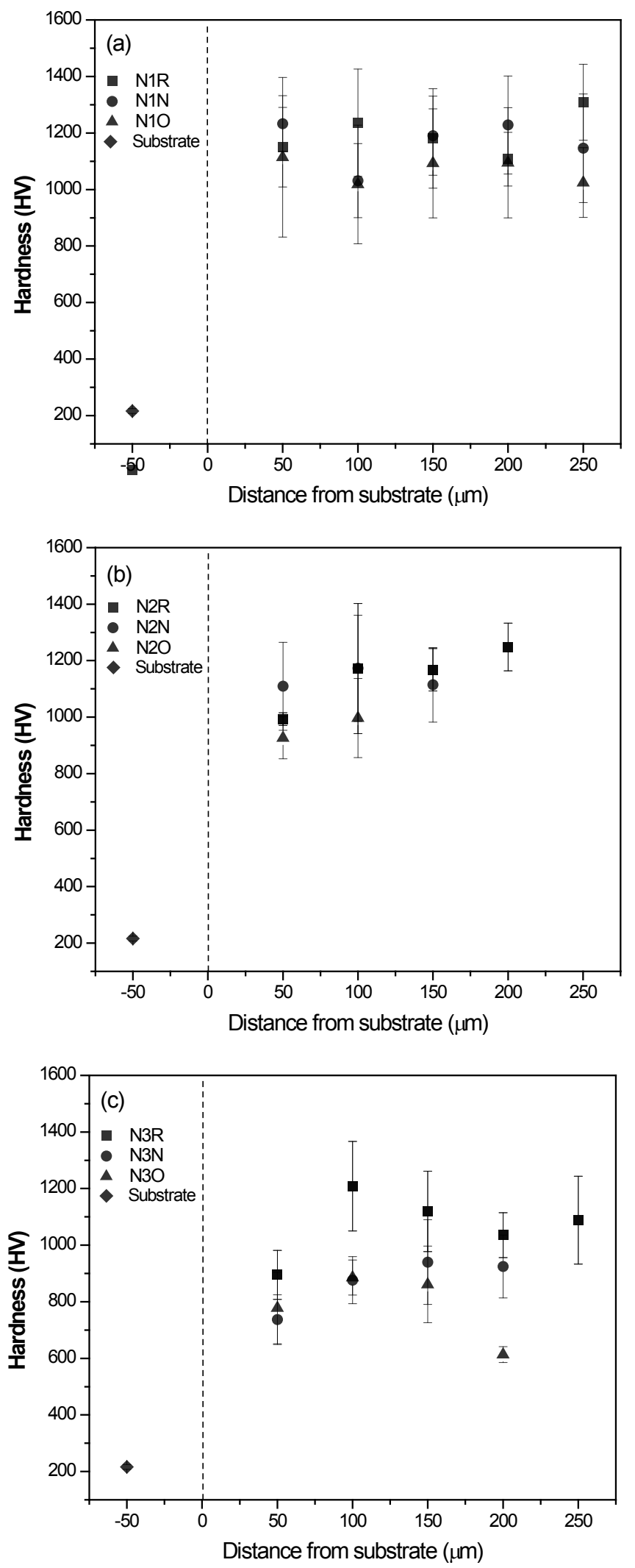

Figure 3. Hardness values obtained for the WC-Co-Cr coatings using nozzle (a) N1; (b) $\mathrm{N} 2$, and (c) N3. 

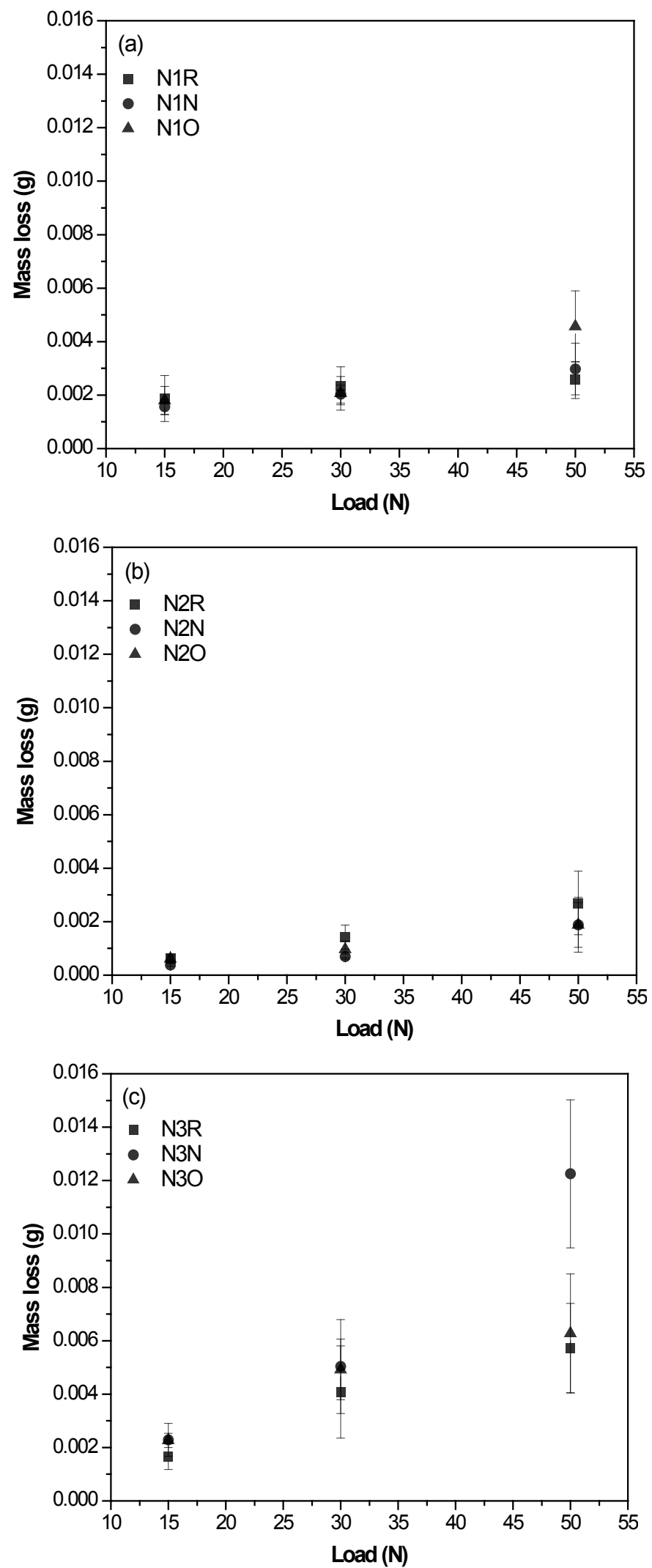

Figure 4. Mass loss as a function of normal load for all assessed coating conditions deposited using nozzle (a) N1; (b) N2, and (c) N3. 
Figure 5 displays the wear debris representative for N1, N2 and N3 conditions. The morphology of the wear debris obtained from N1 and N2 conditions, shown in Figure 5(a), revealed thick flatten and semi-flatten iron-rich debris corresponding to the steel counterpart, along with rounded tungsten-rich debris that belonged to prior WC-Co-Cr coatings. On the contrary, broken tungsten-rich debris resulted from the sliding test of N3 conditions (Figure 5(b)); moreover, the observed Fe-rich debris seemed highly deformed taking flake morphology. It is to be noted that the shape of the debris can be properly correlated to the initial coating microstructure shown in Figure 2. EDS mapping shows that $\mathrm{W}$ is present mainly in the rounded and fragmented debris and the coarser debris is comprised of Fe from the steel counterpart (Figure 5(c) and Figure 5(d)).

At the beginning of the sliding wear testing, the initial contact area between the coating surface and the steel counterpart is developed through the entire coating microstructure. During the relative sliding movement, local contact points are further developed particularly between harder particles (WC surrounded by $\mathrm{W}_{2} \mathrm{C}$ ) and the steel counterface. Localized contact points are due to the severe deformation of the binder and protrusion of the hard particles. Hence, the presence of hard particles against the steel counterpart produced predominantly abrasion wear mechanism and probable tribo-oxidation, which was further confirmed at the steel counterpart surface. Hard particles behave as load-bearing contact points [33] acting against the steel counterpart resulting in the formation of large grooves and further removal of Fe-rich debris (chunk)
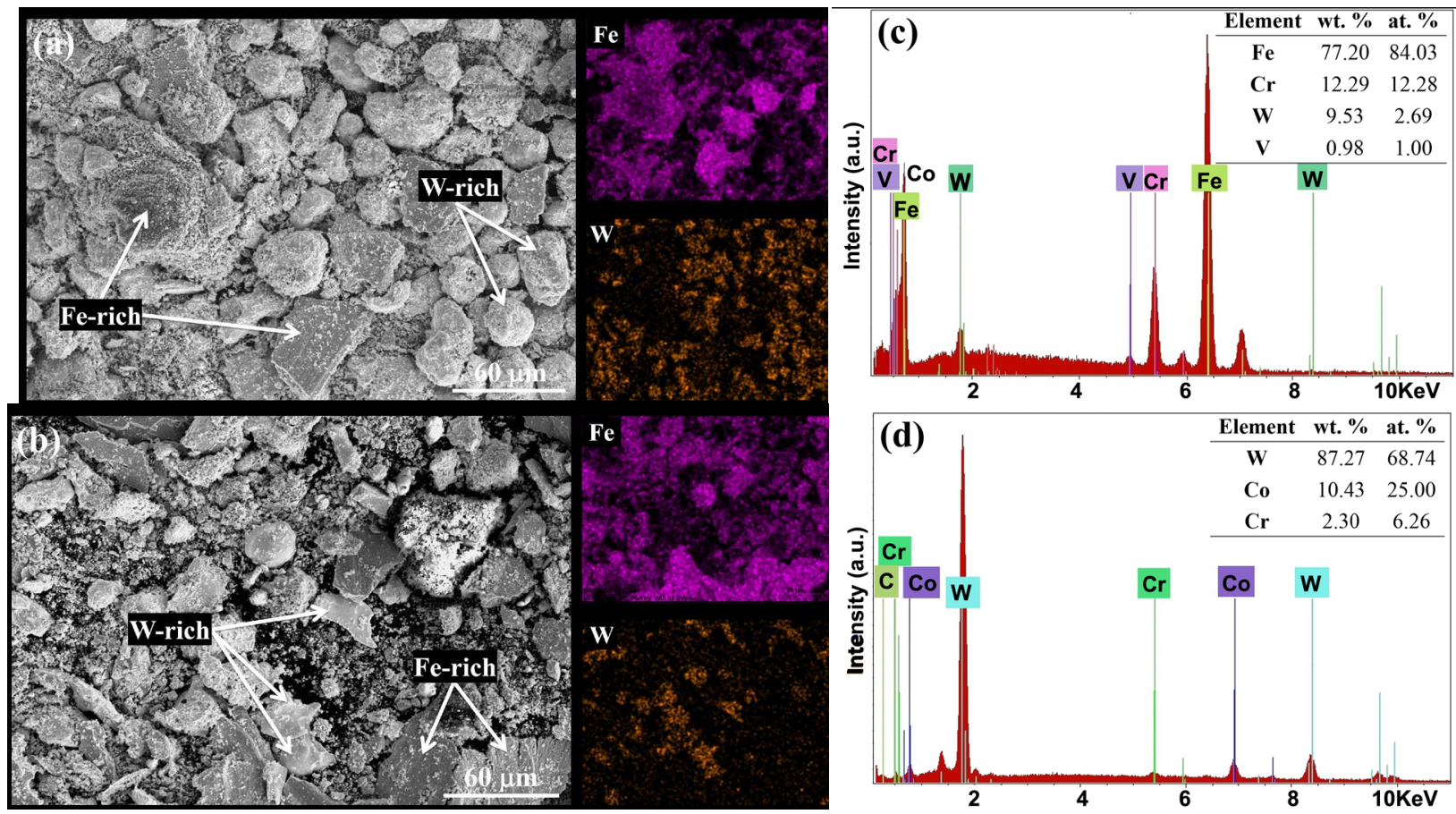

Figure 5. Morphology of wear debris corresponding to: (a) N1 and N2; (b) N3 conditions along with EDS-mapping taken from the corresponding micrograph on the left. Representative EDS spectrum analysis for (c) Fe-rich and (d) W-rich taken from the indicated particles from (a) and (b). 
having thick flatten morphology as depicted in Figure 5(a). Subsequent carbide pullout occurred as the matrix wore, particularly, the spherical un-melted particles were removed from the coating surface thus acting as free abrasive particles among the contact surfaces, traces of such released particles were found among the analyzed debris as shown by Figure 5(a). When this mechanism is concerned, the wear appears to occur by the removal of the binder phase followed by the dislodgement or pull out of the carbide particles. The above mentioned mechanism is predominantly observed for the coatings deposited using $\mathrm{N} 1$ and N2 nozzles which are composed by a large amount of hard carbide particles distributed in the binder along its microstructure, Figures 2(a)-(f).

In contrast, the wear of $\mathrm{N} 3$ coatings primarily arose through particle delamination. As noticed from the XRD analysis and SEM images, these coatings clearly contains a lower concentration of tungsten mono and di-carbide particles within the flattened splats, which indeed provides wear resistance, and the highest $\mathrm{W}$ and $\mathrm{Co}_{3} \mathrm{~W}_{3} \mathrm{C}$ phase content, which has been found to embrittle the binder phase [5] [29]. Therefore, the splats cracked and/or fatigue easily and pulled out from the coating. Similar observations of both described types of wear mechanisms have been reported earlier for WC coatings deposited with different thermal spray techniques [3] [10] [19] [31] [32].

Based on the phase semi-quantification from XRD analysis (Figure 1), higher WC along with $\mathrm{W}_{2} \mathrm{C}$ phase concentrations (i.e. above $70 \%$ ) in addition to low content of $\mathrm{W}$ and $\mathrm{Co}_{3} \mathrm{~W}_{3} \mathrm{C}$ (below $\sim 21$ and $10 \%$, respectively) results in an improved wear behavior for $\mathrm{N} 1$ and $\mathrm{N} 2$ conditions. In particular, the phase content of WC combined with $\mathrm{W}_{2} \mathrm{C}$ for the samples with the lower mass loss (N2) achieved around $82 \%$, while the $\mathrm{N} 3$ attained $~ 35 \%$. Among all conditions tested, the $\mathrm{N} 3$ samples showed the lowest $\mathrm{WC}$ and $\mathrm{W}_{2} \mathrm{C}$ and the highest $\mathrm{W}$ and $\mathrm{Co}_{3} \mathrm{~W}_{3} \mathrm{C}$ phase contents. Then, the relatively lower proportions of $\mathrm{WC}$ along with $\mathrm{W}_{2} \mathrm{C}$ particles influence the final sliding wear behavior upon $\mathrm{N} 3$ conditions. The present results showed that the presence of $\mathrm{W}_{2} \mathrm{C}$ in the coatings appears to be beneficial for the sliding wear resistance under the dry sliding frictional wear behavior of WC-Co-Cr flame spray coatings. Similar results have been reported by Schwetzke and Kreye [5], who found that a decarburization percentage up to $60 \%$ does not affect the wear resistance of HVOF tungsten carbide coatings.

It is worth pointing out that despite the level of porosity for $\mathrm{N} 1$ and $\mathrm{N} 2$ conditions (see Table 1), the sliding wear performance through pin-on-disk configuration was not severely affected (if contrast to N3 condition). Similar results have been reported by Voyer and Marple [20] in which levels of porosity between $6 \%-13 \%$ in WC-12Co coatings resulted in improved sliding wear performance, indeed, the most porous specimens provided the best wear resistance. This however, has been explained and based upon the assumption that porous serve as reservoir for further removed debris during the sliding [20]. At this point, it is interesting to note that most $\mathrm{WC}$ and $\mathrm{W}_{2} \mathrm{C}$-rich debris depicted in Figure 5(a) resulted in rounded shape geometry thus indicating that once the 
removed debris entered the pore and with subsequent movement, those could have served as points of stress concentration that helped on delay the mass loss. However, this phenomenon is not completely understood and additional work is needed to fully clarify the role of porous in WC-Co-Cr flame sprayed coatings subjected to sliding wear.

In general, the sliding wear behavior seems to be controlled by both: the distribution of hard particles in the microstructure and the presence of WC and $\mathrm{W}_{2} \mathrm{C}$ hard phases. $\mathrm{N} 1$ and $\mathrm{N} 2$ conditions are distinguished to have these features while the N3 samples are characterized by a significantly depleted WC morphology and a brittle binder phase with high concentrations of $\mathrm{W}$ and cobalt subcarbides which contributes to inferior wear resistance and particle pullout.

\section{Conclusions}

A systematic study regarding the effect of the flame spray parameters on the microstructure, structure and dry sliding wear behavior of WC-10Co-4Cr coatings was carried out; the following conclusions can be addressed:

1) The microstructure and concentrations of phases in WC-Co-Cr flame spray coatings depend on the deposition parameters, namely, flame chemistry and nozzle exit area of the spray gun.

2) WC particles undergo considerable levels of decarburization during spraying for all considered conditions, in fact, moving from fuel- to oxygen-rich conditions increases the particle temperature thus allowing higher degree of WC decomposition. Fuel-rich flames reduce the heat input during spraying and therefore the degree of $\mathrm{WC}$ decomposition into $\mathrm{W}_{2} \mathrm{C}, \mathrm{W}$ and $\mathrm{Co}_{3} \mathrm{~W}_{3} \mathrm{C}$.

3) The resultant microstructure of the coatings greatly depended on the nozzle employed. Nozzles with a small exit area are associated with a higher particle velocities and hence lower particle temperatures and coatings with a more homogeneous and denser microstructure. Otherwise, higher exit area limit the extent of particle deformation, i.e., large amount of un-melted and semi-molten particles, since low particle velocities are achieved.

4) The sliding wear behavior through pin-on-disk configuration resulted strongly affected by the coating microstructure and the content of hard phases WC and $\mathrm{W}_{2} \mathrm{C}$. The presence of hard phase dispersed in the microstructure was a key factor for conferring superior sliding wear resistance despite the relatively higher porosity content.

5) The phase transformation from $\mathrm{WC}$ to $\mathrm{W}_{2} \mathrm{C}$ seems not to degrade the sliding-wear properties, however, high depletion of WC grains along with a high concentration of $\mathrm{W}$ and $\eta$-phase $\left(\mathrm{Co}_{3} \mathrm{~W}_{3} \mathrm{C}\right)$ within the matrix was observed to deteriorate the wear resistance.

6) The predominant wear mechanism between the contacting surfaces for the coatings deposited with $\mathrm{N} 1$ and $\mathrm{N} 2$ nozzles is due to abrasion of the initial matrix wear, protrusion and further pullout of the hard particles. On the contrary, the wear mechanism of the $\mathrm{N} 3$ conditions is owing to delamination as a result of 
splat cracking and fracture.

It is clear that the microstructure, properties and concentrations of phases in flame spray coatings depend on the deposition parameters. Hence, it is proposed to investigate, prior to coating deposition, the in-flight particle state, i.e., on-line measurements of particle velocity and temperature as a function of the different spraying conditions, in order to deposit coatings with optimal or desired conditions as well as to reduce the number of experiments.

\section{Acknowledgements}

Financial support from Consejo Nacional de Ciencia y Tecnología Mexico under grants no. 270613-INFRA-2016 and 254731-INFRA-2015 is gratefully acknowledged.

\section{References}

[1] Bolelli, G., Cannillo, V., Lusvarghi, L. and Ricco, S. (2006) Mechanical and Tribological Properties of Electrolytic Hard Chrome and HVOF-Sprayed Coatings. Surface and Coatings Technology, 200, 2995-3009. https://doi.org/10.1016/j.surfcoat.2005.04.057

[2] Murthy, J.K.N. and Venkataraman, B. (2006) Abrasive Wear Behaviour of WC-CoCr and $\mathrm{Cr} 3 \mathrm{C} 2-20(\mathrm{NiCr})$ Deposited by HVOF and Detonation Spray Processes. Surface and Coatings Technology, 200, 2642-2652.

https://doi.org/10.1016/j.surfcoat.2004.10.136

[3] Jacobs, L. Hyland, M.M. and De Bonte, M. (1999) Study of the Influence of Microstructural Properties on the Sliding-Wear Behavior of HVOF and HVAF Sprayed WC-Cermet Coatings. Journal of Thermal Spray Technology, 8, 125-132. https://doi.org/10.1361/105996399770350656

[4] Kumari, K., Anand, K., Bellacci, M. and Giannozzi, M. (2010) Effect of Microstructure on Abrasive Wear Behavior of Thermally Sprayed WC-10Co-4Cr Coatings. Wear, 268, 1309-1319. https://doi.org/10.1016/j.wear.2010.02.001

[5] Schwetzke, R. and Kreye, H. (1999) Microstructure and Properties of Tungsten Carbide Coatings Sprayed with various High-Velocity Oxygen Fuel Spray Systems. Journal of Thermal Spray Technology, 8, 433-439. https://doi.org/10.1361/105996399770350395

[6] Kim, H.J., Kweon, Y.G. and Chang, R.W. (1994) Wear and Erosion Behavior of Plasma-Sprayed WC-Co Coatings. Journal of Thermal Spray Technology, 3, 169-178. https://doi.org/10.1007/BF02648274

[7] Wayne, S.F. and Sampath, S. (1992) Structure/Property Relationships in Sintered and Thermally Sprayed WC-Co. Journal of Thermal Spray Technology, 1, 307-315. https://doi.org/10.1007/BF02647158

[8] Suresh Babu, P., Basu, B. and Sundararajan, G. (2010) Abrasive Wear Behavior of Detonation Sprayed WC-12Co Coatings: Influence of Decarburization and Abrasive Characteristics. Wear, 268, 1387-1399. https://doi.org/10.1016/j.wear.2010.02.013

[9] Nerz, J., Kushner, B. and Rotolico, A. (1992) Microstructural Evaluation of Tungsten Carbide-Cobalt Coatings. Journal of Thermal Spray Technology, 1, 147-152. https://doi.org/10.1007/BF02659015

[10] Picas, J.A., Xiong, Y., Punset, M., Ajdelsztajn, L., Forn, A. and Schoenung, J.M. (2009) Microstructure and Wear Resistance of WC-Co by Three Consolidation 
Processing Techniques. International Journal of Refractory Metals and Hard Materials, 27, 344-349. https://doi.org/10.1016/j.ijrmhm.2008.07.002

[11] Culliton, D., Betts, A., Carvalho, S. and Kennedy, D. (2013) Improving Tribological Properties of Cast Al-Si Alloys through Application of Wear-Resistant Thermal Spray Coatings. Journal of Thermal Spray Technology, 22, 491-501. https://doi.org/10.1007/s11666-013-9894-y

[12] Rodríguez, J., Martín, A., Fernández, R. and Fernández, J.E. (2003) An Experimental Study of the Wear Performance of NiCrBSi Thermal Spray Coatings. Wear, 255, 950-955. https://doi.org/10.1016/S0043-1648(03)00162-5

[13] Miranda, J.C. and Ramalho, A. (2001) Abrasion Resistance of Thermal Sprayed Composite Coatings with a Nickel Alloy Matrix and a WC Hard Phase. Effect of Deposition Technique and Re-Melting, Tribology Letters, 11, 37-48. https://doi.org/10.1023/A:1016692304440

[14] Pawlowski, L. (2008) The Science and Engineering of Thermal Spray Coatings. Wiley, England. https://doi.org/10.1002/9780470754085

[15] Bradai, M.A., Sadeddine, A., Benabbas, A., Bounar, N. and Mammeri, A. (2011) Microstructural and Mechanical Properties of Ni-Base Thermal Spray Coatings Deposited by Flame Spraying. Metallurgicaland Materials Transactions B, 42B, 932-938.

[16] Li, C.J., Ohmori, A. and Harada, Y. (1996) Effect of Powder Structure on the Structure of Thermally Sprayed WC-Co Coatings. Journal of Materials Science, 31, 785-794. https://doi.org/10.1007/BF00367900

[17] De Villiers Lovelock, H.L. (1998) Powder/Processing/Structure Relationships in WC-Co Thermal Spray Coatings: A Review of the Published Literature. Journal of Thermal Spray Technology, 7, 357-373. https://doi.org/10.1361/105996398770350846

[18] Sudaprasert, T., Shipway, P.H. and McCartney, D.G. (2003) Sliding Wear Behaviour of HVOF Sprayed WC-Co Coatings Deposited with both Gas-Fuelled and Liquid-Fuelled Systems. Wear, 255, 943-949. https://doi.org/10.1016/S0043-1648(03)00293-X

[19] Thakur, L. and Arora, N. (2013) Sliding and Abrasive Wear Behavior of WC-CoCr Coatings with Different Carbide Sizes. Journal of Materials Engineering and Performance, 22, 574-583. https://doi.org/10.1007/s11665-012-0265-5

[20] Voyer, J. and Marple, B.R. (1999) Sliding Wear Behavior of High Velocity Oxy-Fuel and High Power Plasma Spray-Processed Tungsten Carbide-Based Cermet Coatings. Wear, 225-229, 135-145. https://doi.org/10.1016/S0043-1648(99)00007-1

[21] Verdon, C., Karimi, A. and Martin, J. (1998) A Study of High Velocity Oxy-Fuel Thermally Sprayed Tungsten Carbide Based Coatings. Part 1: Microstructures. Materials Science and Engineering A, 246, 11-24. https://doi.org/10.1016/S0921-5093(97)00759-4

[22] Jacobs, L., Hyland, M.M. and De Bonte, M. (1998) Comparative Study of WC-Cermet Coatings Sprayed via the HVOF and the HVAF Process. Journal of Thermal Spray Technology, 7, 213-218. https://doi.org/10.1361/105996398770350954

[23] Planche, M.P., Liao, H., Normand, C. and Coddet, C. (2005) Relationships between NiCrBSi Particle Characteristics and Corresponding Coatings Properties Using Different Thermal Spraying Processes. Surface and Coatings Technology, 200, 2465-2473. https://doi.org/10.1016/j.surfcoat.2004.08.224 
[24] Guo, D.Z., Li, F.L., Wang, J.Y. and Sun, J.S. (1995) Effects of Post-Coating Processing on Structure and Erosive Wear Characteristics of Flame and Plasma Spray Coatings. Surface and Coatings Technology, 73, 73-78. https://doi.org/10.1016/0257-8972(94)02364-6

[25] Ruiz-Luna, H., Lozano-Mandujano, D., Alvarado-Orozco, J.M., Valarezo, A., Poblano-Salas, C., Trápaga-Martínez, L.G., Espinoza-Beltrán, F.J. and Muñoz-Saldaña, J. (2014) Effect of HVOF Processing Parameters on the Properties of NiCoCrAlY Coatings by Design of Experiments. Journal of Thermal Spray Technology, 23, 950-961. https://doi.org/10.1007/s11666-014-0121-2

[26] Valarezo, A., Choi, W.B., Chi, W., Gouldstone, A. and Sampath, S. (2010) Process Control and Characterization of NiCr Coatings by HVOF-DJ2700 System: A Process Map Approach. Journal of Thermal Spray Technology, 19, 852-865. https://doi.org/10.1007/s11666-010-9492-1

[27] Berget, J., Rogne, T. and Bardal, E. (2007) Erosion-Corrosion Properties of Different WC-Co-Cr Coatings Deposited by the HVOF Process-Influence of Metallic Matrix Composition and Spray Powder Size Distribution. Surface and Coatings Technolo$g y, 201,7619-7625$. https://doi.org/10.1016/j.surfcoat.2007.02.032

[28] Kear, B.H., Skandan, G. and Sadangi, R.K. (2001) Factors Controlling Decarburization in HVOF Sprayed Nano-WC/Co Hardcoatings. Scripta Materialia, 44, 1703-1707. https://doi.org/10.1016/S1359-6462(01)00867-3

[29] Stewart, D.A., Shipway, P.H. and McCartney, D.G. (2000) Microstructural Evolution in Thermally Sprayed WC-Co Coatings: Comparison between Nanocomposite and Conventional Starting Powders. Acta Materialia, 48, 1593-1604. https://doi.org/10.1016/S1359-6454(99)00440-1

[30] Mott, R. (1996) Applied Fluid Mechanics. Prentice Hall Career \& Technology, Englewood Cliffs.

[31] Lee, C.W., Han, J.H., Yoon, J., Shin, M.C. and Kwun, S.I. (2010) A Study on Powder Mixing for High Fracture Toughness and Wear Resistance of WC-Co-Cr Coatings Sprayed by HVOF. Surface and Coatings Technology, 204, 2223-2229. https://doi.org/10.1016/j.surfcoat.2009.12.014

[32] Liu, S.L., Zheng, X.P. and Geng, G.Q. (2010) Influence of Nano-WC-12Co Powder Addition in WC-10Co-4Cr AC-HVAF Sprayed Coatings on Wear and Erosion Behaviour. Wear, 269, 362-367. https://doi.org/10.1016/j.wear.2010.04.019

[33] Sarkar, A.D. (1980) Friction and Wear. Academic Press, Inc., London. 